\title{
INTUIÇÃO E CRIAÇÃO: A FILOSOFIA COMO ATO DE RESISTÊNCIA
}

\author{
Pablo Enrique Abraham Zunino (UFRB) ${ }^{1}$
}

\begin{abstract}
RESUMO: O objetivo deste artigo é indagar de que maneira a filosofia pode ser compreendida como um ato de resistência. Deleuze introduz essa tese, ao aproximar a filosofia da arte, porquanto ambas são atos de criação. Nesse sentido, o método filosófico de Bergson - a intuição - já indica um tipo de atividade filosófica que se caracteriza, antes de tudo, pela criação de conceitos. Ora, como é que um conceito filosófico pode constituir um ato de resistência? Para responder a essa questăo, retomamos uma análise sobre a relação entre o método de intuição e a criação artística, seguida da interpretação deleuziana acerca do que significa ter uma ideia. Contudo, a passagem da ideia ao ato de resistência exige uma transposição do plano teórico para o plano concreto. Com esse intuito, focalizamos um exemplo sugerido pela filosofia de Bergson: a ideia de um possível retorno à vida simples. Isso nos permitirá avaliar até que ponto uma ideia filosófica pode ser confrontada com a realidade no mundo atual e, nesse sentido, entendida como um ato de resistência.
\end{abstract}

PALAVRAS-CHAVE: Filosofia. Arte. Criação. Resistência. Vida simples.

\section{INTRODUÇÁO}

As ideias de tempo mecânico e de tempo lento podem ser pensadas no horizonte da oposição bergsoniana entre aquilo que é repetitivo, de um lado, como o trabalho, e, de outro, aquilo que denota um processo interno de diferenciação, como o pensamento filosófico e a criação artística. Com efeito, a relação entre o artista e a obra de arte exige que se distinga de antemão a mera descoberta da verdadeira invenção: "A descoberta refere-se àquilo que já existe atual ou virtualmente: ela certamente viria mais cedo ou mais tarde. A invenção doa o ser àquilo que náo existia, e poderia nunca vir." (GOUHIER, 1989, p. 60). Na medida em que o artista é o inventor da sua obra, o espírito de invenção se manifesta naturalmente na arte, isto é, no ato criativo, mas é assim que podemos entender também o método filosófico de Bergson - a intuição, com base no modelo da criação e no espírito de invenção:

\footnotetext{
${ }^{1}$ Graduou-se (2003) e obteve os títulos de Mestre (2006) e Doutor (2010) em Filosofia pela Universidade de Sáo Paulo. Durante o Doutorado, fez um estágio de pesquisa na Universidade Paris 1 - Panthéon-Sorbonne, com apoio do CNPq. Publicou o livro Bergson: a metafísica da ação (Humanitas, 2012) e foi pesquisador bolsista (FAPESP) do Programa de Pós-Doutorado do Departamento de Filosofia da USP. Atualmente, é Professor Adjunto da Universidade Federal do Recôncavo da Bahia, atuando principalmente nos seguintes temas: subjetividade, temporalidade, Bergson e Deleuze. E-mail: pablo@ufrb.edu.br
}

http://dx.doi.org/10.1590/S0101-31732017000400009 
O estatuto da obra de arte e do artista náo podem ser entendidos como uma psicologia do ato criador. [...] $\mathrm{O}$ que mais interessa à concepção bergsoniana da arte não é a gestação individual da obra, mas o processo de identificação com a totalidade da qual a obra se faz veículo de revelação. Nesse sentido todo artista, no plano da expressão, já é um intérprete de si mesmo, da mesma forma que o filósofo, quando expressa sua intuição fundamental em sistema, já é um discípulo de si mesmo. [...] A obra de arte, o artista são manifestaçóes da continuidade do Ato Criador. (LEOPOLDO E SILVA, 1994, p. 325-326).

Talvez por isso Deleuze (1999, p. 4-5) tenha definido a filosofia como uma disciplina que consiste em criar ou inventar conceitos. De fato, costumase dizer que ter uma intuição é ter uma ideia, no entanto, o que é exatamente "ter uma ideia"? Notemos, antes de tudo, que a criação enquanto processo não supóe necessariamente um criador, uma vez que o sujeito passa a ser ele mesmo efeito do processo criativo. Abandona-se de saída o pressuposto de um sujeito relaxado e passivo como substrato de uma ação espontânea, mas também a intenção ou a finalidade perseguida pela ação voluntária. Para compreender essa experiência "sem piloto", a qual independe da vontade de um eu, podemos pensar nos artistas que se dizem tomados por ideias como se elas os invadissem. Ter uma ideia náo resulta de um processo de busca ativa, já que o ato criador se assemelha mais a um encontro do que ao resultado de uma busca. Isso não significa que a ideia surja espontaneamente: "Não é uma busca orientada, mas também não é uma simples espera. Trabalha-se para ter a possibilidade de receber a idéia. Melhor seria referir-se a uma ativa receptividade." (KASTRUP, 2007, p. 62).

Pensemos na atitude de um caminhante urbano. De um lado, temos o trabalhador que se dirige quase automaticamente do lar até o local de trabalho, seguindo uma linha reta; de outro, o turista, que é completamente seduzido pela cidade e passeia aleatoriamente por ela; entre esses dois extremos, estaria o caminhar do antropólogo, aquele que parece distraído como um turista, mas está à espreita do insólito, como um caçador, deixando sempre uma margem para o inesperado. Nesse sentido, o ato criativo tem algo de intuitivo, isto é, uma "[...] atenção ao mesmo tempo concentrada e sem foco, como aquela que caracteriza a meditação budista.” (KASTRUP, 2007, p. 62). Haveria um aspecto positivo da distração, na medida em que esta permite captar tudo aquilo que está fora de foco e, desse modo, se distingue da simples dispersão: "A distração é um funcionamento em que a atenção vagueia, experimenta 
uma errância, fugindo do foco da tarefa e indo na direção de um campo mais amplo." (KASTRUP, 2007, p. 62). A criação, portanto, envolve um trabalho de composição, pois a ideia não é o pensado, mas o que faz pensar. Ela cria uma necessidade que impulsiona o trabalho para além da vontade pessoal do criador. Mais do que o esforço consciente, o que importa é propiciar o encontro:

O encontro é o refluxo da busca, pois nele somos receptivos. Há então um ritmo. Buscando uma coisa, podemos encontrar outra e reorientar todo o processo. [...] Não podemos ser completamente ativos num encontro, mas devemos deixar-nos afetar pelo que encontramos. (KASTRUP, 2007, p. 66-67).

Ao contrapor à atitude de busca uma atitude de encontro, essa análise atenua a oposição entre tensão e relaxamento. Isso permite confirmar a tese de Bergson segundo a qual haveria uma "atenção suplementar" para além da atenção à vida prática, isto é, para além do alcance funcional e utilitário da experiência. Essa atenção suplementar é a que caracteriza a intuição como uma "percepção alargada", tal como a que possuem naturalmente os artistas. (BERGSON ,2006, p. 155). ${ }^{2}$

\section{I - O CINEMA COMO OBRA DE ARTE: O QUE É TER UMA IDEIA?}

Na conferência de 1987 - $O$ ato de criação, Deleuze compara o trabalho filosófico ao trabalho do artista, mas não se trata em nenhum dos casos de uma criação gratuita. Ao contrário, todo criador responde a uma necessidade de criação: "Um criador só faz aquilo de que tem absoluta necessidade." (DELEUZE, 1999, p. 6).

Falávamos há pouco do que significa ter uma ideia e agora podemos aprofundar mais esse tema, levando em conta alguns exemplos deleuzianos: quando um diretor de cinema faz uma adaptação de um romance, ele está tendo uma ideia? Certamente, pois as ideias em cinema "fazem eco" do que o romance apresenta como ideias literárias. Esse "encontro" ao qual nos referimos antes explica a afinidade intelectual de alguns cineastas com escritores famosos, como a de Akira Kurosawa com Shakespeare e Dostoievski, para seguir o

\footnotetext{
${ }^{2} \mathrm{O}$ tema desta introdução é um desdobramento do texto apresentado no XVI Encontro Nacional da ANPOF: Campos do Jordão, 2014. A versão integral desse trabalho foi submetida para publicação nos Anais do evento.
} 
exemplo de Deleuze. ${ }^{3}$ Vou supor que ninguém assistiu aos filmes nem leu os autores mencionados. Mesmo porque o meu ponto não é a discussão analítica dos filmes e, sim, compreender de que maneira isso se relaciona com a filosofia como criação de conceitos e com o método bergsoniano da intuição.

Os personagens desses romances são sempre "vítimas de uma urgência", quer dizer, eles sabem que há uma questão mais urgente para além das que acontecem na superfície da trama, mas eles não sabem exatamente qual é essa questão. Nisso consiste o encontro entre cinema e literatura: "um belo encontro" que leva o cineasta a adaptar o romance, porque percebe que há um "problema em comum”, aquele que é mais urgente e é preciso que os personagens saibam qual é. Retenhamos essa necessidade do cinema: uma ideia em cinema pode ser tomada de empréstimo de um escritor, cujos personagens estáo em situaçáo de urgência e são afligidos por uma questão mais profunda. ${ }^{4}$

Para levar adiante uma ideia em cinema, existem alguns recursos cinematográficos, como, por exemplo, a disjunção entre o visual e o sonoro, entre ver e falar. $\mathrm{O}$ cinema pode sobrepor aquilo que nos falam àquilo que nos fazem ver, obtendo efeitos especificamente cinematográficos. Quando vemos apenas imagens da terra deserta, não sabemos o que está debaixo dela. Todavia, se uma voz nos fala de cadáveres, qualquer vento ou sulco nessa terra adquire todo o seu sentido.

$\mathrm{O}$ que isso quer dizer? Que ter uma ideia não é da natureza da comunicação, pois a comunicação supôe a transmissão e a propagação de uma informação, a qual, por sua vez, se define como um conjunto de palavras de ordem. Informar, portanto, é fazer circular uma palavra de ordem. Todos nós recebemos "comunicados": comunicado da polícia, da escola, do chefe, do diretor etc. Quando nos comunicam informaçóes, elas nos dizem aquilo em que devemos crer ou pelo menos fazer como se acreditássemos.

Esse é um tema bem atual, porque vivemos precisamente sob o domínio de certos sistemas de informação que, em conjunto, formam um sistema de controle. O que acontece quando cai o sistema? Para tudo! Somos

\footnotetext{
${ }^{3}$ Para um aprofundamento da análise deleuziana do cinema japonês, inclusive o de Kurosawa, cf. Deleuze (1985).

${ }^{4}$ Outro diretor citado por Deleuze, Vicente Minnelli, teve uma ideia sobre o sonho, na verdade, sobre aqueles que não sonham: "[...] sempre que há o sonho do outro, há perigo" - "To dormindo, to sonhando, táo falando mal de mim” (Cantiga de Capoeira). Que os outros sonhem é algo perigoso, porque no sonho dos outros há uma certa "vontade de potência" que pode tornar-nos vítima do sonho dos outros.
} 
dependentes do sistema e das informaçóes contidas nele (datas, prazos, documentos, fotos etc.). Isso lembra as famosas análises de Foucault sobre a "sociedade disciplinar", a qual se caracteriza por dois aspectos: vigilância e reclusão. (FOUCAULT, 1999) $)^{5}$ A vigilância permanente garante o exercício de poder em todos os meios de enclausuramento: prisóes, escolas, oficinas e hospitais. Entretanto, também está presente em nosso dia a dia: câmeras de vídeo por todos os lados ou apenas um cartaz informando: Sorria, você está sendo filmado!

Contudo, alerta-nos Deleuze, essa não era a última palavra de Foucault. Apesar de existirem resquícios da sociedade disciplinar, na atualidade, ela não é eterna. Atualmente, nossa vida se desenrola numa sociedade de outro tipo, a qual poderíamos chamar de "sociedade de controle". Aqueles que nos "cuidam" já não têm necessidade dos meios de enclausuramento: prisóes, escolas e hospitais que, inclusive, são temas de discussão e debate permanente. A sociedade do futuro (a nossa) vai estender esse tratamento aos domicílios. Os empregados não vão mais trabalhar nas oficinas ou nas fábricas, eles podem trabalhar e estudar em casa. A formação permanente não implica um local de clausura. Controle não é disciplina. A imagem da sociedade de controle é uma estrada que multiplica os meios de controle sem enclausurar pessoas. Numa estrada, "[...] as pessoas podem trafegar até o infinito e 'livremente', sem a mínima clausura, e serem perfeitamente controladas.” (DELEUZE, 1999, p.12).

O que era mesmo informação? Algo como uma estrada, isto é, o sistema controlado das palavras de ordem que têm curso numa dada sociedade. E o que tem a ver a obra de arte e a filosofia com tudo isso? Arte e filosofia têm a ver com a contrainformação. Sempre que vivemos sob uma ditadura (como a

\footnotetext{
${ }^{5} \mathrm{Na}$ sociedade de soberania, exaltava-se a vitória do poder soberano, representado pelo Rei ou pela família real. Através de um espetáculo em praça pública, mostra-se o suplício do corpo (tortura, forca, guilhotina) como símbolo da Majestade do Príncipe. A justiça (símbolo da balança: olho por olho, dente por dente; aqui se faz, aqui se paga) é aplicada como uma forma de vingança, pela qual se estabelece o equilíbrio entre o crime cometido e o poder de mostrar ao público como se deve tratar aquele que ousa ultrajá-lo. Na sociedade disciplinar, há um deslocamento do corpo supliciado para o corpo disciplinado, isto é, a supressão do espetáculo dá lugar a uma nova punição mais eficaz e menos sangrenta, que é a penalidade como ato administrativo do Estado. A vingança do soberano é substituída pela noção de "dispositivo", ou seja, um aparelho de visão mais abrangente que favorece o exercício de poder, na medida em que imprime a consciência de "estar sendo vigiado" a quem se aplica. O panoptismo é um dispositivo de poder disciplinar que permite ver de todos os ângulos, sem ser visto: "Somos suas engrenagens", diz Foucault, porque lhe concedemos e renovamos seus efeitos de poder. Trata-se de uma nova tecnologia punitiva, que garante visibilidade absoluta no espaço com base no modelo arquitetônico, mas possibilita pensar o exercício de poder na contemporaneidade (ORWELL, 2003; HUXLEY, 1995).
} 
ditadura militar dos países da América Latina), existe a contrainformação. Os primeiros judeus que chegavam da Alemanha, na época de Hitler, contavam histórias sobre os campos de extermínio: eles faziam a contrainformação. No entanto, a contrainformação nunca é suficiente para mudar a situação, exceto quando ela se torna um "ato de resistência", algo que já não é nem informação, nem contrainformação.

Vimos que a obra de arte (em especial, o cinema) não é um instrumento de comunicação, pois ela não informa nada. Em compensação, ela pode ser pensada como um ato de resistência. Ora, que relaçáo misteriosa é essa entre arte e ato de resistência, se os homens que resistem náo têm nem tempo nem cultura para relacionar-se com a arte?

O escritor André Malraux (1901-1976) diz que a arte é a única coisa que resiste à morte. Isso é um "belo conceito filosófico", reconhece Deleuze, ao afirmar que fazer filosofia é criar ou inventar conceitos. A arte é aquilo que resiste, daí a relação entre a obra de arte e o ato de resistência: basta contemplar uma estatueta de 3000 anos antes de Cristo.

E o que era ter uma ideia em cinema? Usar, por exemplo, o efeito da disjunção entre voz sonora (narrador) e imagem visual e fazer com que uma voz se erga no ar cada vez mais, enquanto a imagem se afunda na terra. Isso é um ato de resistência, um ato de fala que possui duas faces: ele é humano, mas também é um ato de arte, porque se pode resistir à morte de duas maneiras: na forma de uma obra de arte ou como uma luta entre os homens.

É verdade que essa luta entre os homens se relaciona com a obra de arte de modo bem enigmático, no apelo final de Deleuze a uma frase de Paul Klee (pintor e poeta suíço, 1879-1940): "Pois bem, falta o povo." No entanto, o mistério se dissipa, ao compreendermos que "não existe obra de arte que não faça apelo a um povo que ainda não existe”.

\section{II - A FILOSOFIA COMO ATO DE RESISTÊNCIA: LEI DA DICOTOMIA E RETORNO À VIDA SIMPLES}

Proponho, nesta segunda parte do artigo, retornar à obra de Bergson $(1932)^{6}$, já munidos desses três conceitos deleuzianos: a filosofia como ato de resistência, a luta entre os homens e o apelo a um povo que ainda não existe.

${ }^{6}$ BERGSON, H. As duas fontes da moral e da religião (1932), último capítulo. Doravante, citado como DF. 
Nas últimas duas décadas, vimos a humanidade atingir um desenvolvimento tecnológico comparável ao que, meio século atrás, poderia ser considerado ficção científica: internet, robótica, nanotecnologia etc. Entretanto, todo esse desenvolvimento técnico e científico é incapaz de superar problemas básicos da humanidade, tais como a fome, as guerras e a poluição do meio ambiente. Entre os pensadores contemporâneos, talvez tenha sido Bergson o primeiro a apontar os riscos de uma possível autodestruição da humanidade, que há muito tempo se tornou a principal ameaça para a conservação da vida das outras espécies e do próprio planeta. Haveria um descompasso entre o desenvolvimento material e o desenvolvimento espiritual, desde que o homem moderno se deixou seduzir por um modo de vida baseado na produção e no consumo desenfreados.

Será que existe algum propósito de ordem espiritual, por trás desse sistema de produtividade industrial e técnico ao qual chegamos? Difícil de aceitar. Basta olhar os países desenvolvidos e seu modo de vida para indagarmos onde é que esse desígnio espiritual foi se esconder. Segundo Bergson, um acidente de aiguillage (ação de mover as linhas férreas) fez com que todos se deixassem fascinar pelo desejo e pelo luxo: “Toda nossa civilização é afrodisíaca." Em vez de garantir a todos o sustento necessário, o industrialismo seduziu o homem com necessidades supérfluas (WATERLOT, 2008, p. 35-39).

Ascetismo e conforto teriam ambos uma origem comum: cada uma dessas tendências corresponde a um dos elementos necessários ao acabamento da humanidade. Não há vida espiritual possível sem estabilidade material e, inversamente, não há tranquilidade material sensata sem relação com um objetivo espiritual. Como a humanidade é uma só, essas tendências não ocorrem simultaneamente, mas sucessivamente. Assim, o desenvolvimento histórico da humanidade pode ser visto como uma progressão em espiral: uma fase de ascetismo, depois uma fase de enriquecimento, desejo e conforto. Cada fase prossegue até o fim de si mesma e só se detém quando há uma impossibilidade de continuar. Cabe perguntar então se saberemos, antes que seja tarde para o nosso meio ambiente, voltar a uma vida simples, graças à qual não nos destruamos a nós mesmos.

Muitos acreditam que já é tarde demais. Entretanto, 80 anos atrás, Bergson não se deixou intimidar por essas "sirenas de pessimismo", quando viu a Europa levantar os braços ao fascismo e a ciência inventar uma arma secreta capaz de exterminar o adversário na próxima guerra. De lá para cá, a populaçáo sempre crescente tem cada vez menos acesso aos recursos naturais, 
antigas guerras por território continuam levando uns a massacrar os outros, novos conflitos bélicos surgem aqui e ali, em nome da democracia, porém, camuflando a sede capitalista por petróleo.

Faz um bom tempo que estamos nessa encruzilhada: o desenvolvimento frenético da tendência que visa ao luxo já começou a causar mais danos do que benefícios (excesso de lixo, doenças crônicas e degenerativas provocadas pelo sedentarismo e a má alimentação, agravamento dos distúrbios mentais, tais como a depressão e a ansiedade etc.). Há quem acredite numa regulamentação política internacional capaz de impedir as constantes ameaças contra os recursos naturais, como as florestas e as fontes de água potável - em muitas áreas, já poluídas; em outras, como São Paulo, abaixo do volume morto. Não obstante, essa solução nem sempre é tão eficaz, porque o dinheiro e a corrupção falam mais alto.

Haveria talvez uma outra via, sem dúvida carregada daquele otimismo bergsoniano, a qual não se deixou levar pela enxurrada das guerras e hoje lampeja fragilmente no horizonte, como uma estrela distante que não podemos alcançar. Esse seria o retorno à vida simples: uma ideia filosófica, um ato de resistência à espera de um povo que ainda não existe. É claro que esse retorno não supóe uma abnegação imediata de todos os prazeres da vida terrena, nem alimenta nostalgias pela época dos nossos avós. Trata-se do caminhar errante da sociedade como um todo, guiada pelo impulso de vida que se manifesta de tempos em tempos e, como a proa de um navio, abre as águas do oceano, levando consigo a humanidade desvairada.

A "lei da dicotomia" revela uma luta entre os homens, na qual se opóem duas tendências contrárias, isto é, o "aspecto superficial de um progresso" que não se reduz à corrida pelo bem-estar liderada pela ciência. Esse frenesi é apenas a continuação de outro, que predominou na Idade Média e cujo ideal de ascetismo também conduziu a certos exageros frenéticos, acabando por diluir-se na indiferença geral nas condições materiais da existência. Trata-se, portanto, de um "progresso por oscilação": depois da complicação crescente, haverá um retorno à simplicidade.

Para caracterizar o que entendemos aqui por "simplicidade", vamos comentar quatro aspectos que denotam um processo de simplificação daquilo que já se tornou complexo (porque ser simples não é tão simples): ${ }^{7}$

7 Uma versão preliminar e mais completa desta parte do trabalho foi apresentada no I EFIBA Encontro de Filosofia da Bahia, na UEFS: Feira de Santana, setembro de 2014. O texto integral, com 
1) Reforma da nossa alimentação. Além do consumo exagerado de carne, o cozimento dos alimentos reduz o teor de vitaminas presentes nos alimentos crus, o que interfere negativamente em nossa saúde: "A reforma de nossa alimentação já teria repercussões incontáveis em nossa indústria, nosso comércio, nossa agricultura, no sentido de consideráveis simplificações." (DF, 1932, p. 229).

2) As relaçôes entre luxo, prazer e bem-estar estão implicadas na crítica de Bergson à galanteria masculina. Questôes como sexualidade, obsessão pelo prazer, natalidade e controle demográfico se articulam com a necessidade crescente de evitar o desperdício e náo despertar a inveja. Ora, como agradar alguém, sem apelar para a ostentação material e a cultura egocêntrica?

A mulher apresará a chegada dessa hora [abandono do amor pelo prazer] na medida em que queira realmente, sinceramente, tornar-se igual ao homem, em vez de continuar o instrumento que é agora, esperando vibrar sob o arco do músico. Opere-se a transformação: nossa vida será mais séria ao mesmo tempo que mais simples. O que a mulher exige de luxo para agradar ao homem e, por ressonância, para agradar a si mesma tornar-se-á em grande parte inútil. (DF, 1932, p. 229).

3) Dizem que a América foi descoberta por acaso, quando o homem estava à procura de especiarias: gengibre, cravo, pimenta e canela. Mas quem se importa hoje com esses temperos que podem ser comprados por moedas, em qualquer feira de esquina? É isso que nos dá certa esperança: ver como uma loucura chama a loucura antagônica, porque os gostos que nos parecem definitivos são sempre passageiros.

4) Na época de Bergson, o carro era a última maravilha da mecânica. Ainda hoje, o carro é muito mais um símbolo de status do que um meio de transporte eficaz, visto que o trânsito caótico das grandes cidades exige mudanças no comportamento das pessoas. $\mathrm{O}$ retorno ao uso da bicicleta (simplicidade), há muito tempo valorizado em outros países, é motivo de controvérsias no Brasil, porque a criação de ciclovias ameaça o conforto daqueles que preferem ir de carro até à padaria da esquina, mas não encontram lugar para estacionar. Será que o carro no futuro se tornará um objeto tão comum como são hoje o cravo e a canela? Difícil de acreditar. Ou será que já é assim e, por isso, temos tanto engarrafamento nas ruas?

algumas adaptaçôes, poderá ser publicado futuramente. 
Dessa maneira, constatamos "a satisfação de um luxo oriunda de uma invenção mecânica”. As descobertas da ciência sugerem cada vez mais invençôes, por isso, nunca conseguiremos satisfazer nossas antigas necessidades, porque sempre haverá criação de necessidades novas. ${ }^{8}$ A questão é saber se o espirito de invenção suscita essas necessidades artificiais ou se não seria a necessidade artificial que teria orientado o espírito de invenção nessa direção. Para Bergson, essa segunda hipótese é a mais provável, já que pode ser confirmada, ao refletirmos sobre as origens do maquinismo.

A invenção mecânica seria um "dom natural" que começa por utilizar energias visíveis, tais como o esforço muscular, a força do vento ou uma queda d'água. Entretanto, ela se intensifica, quando utiliza energias potenciais, como o carvão e o petróleo (ZUNINO, 2014). Foi isso que permitiu a invençáo da máquina a vapor, símbolo da Revolução Industrial. Todavia, a máquina fez pouco para aliviar o fardo do homem, se levarmos em conta que ainda hoje muitos morrem de fome. $\mathrm{Na}$ verdade, a indústria fabrica para vender e não para prestar serviços à humanidade. Isso talvez tenha ocasionado o desvio do industrialismo, o qual se limitou a estimular o consumo supérfluo, incrementar o luxo e favorecer as cidades em detrimento dos campos, transformando as relaçóes entre patrấo e empregado, entre o capital e o trabalho, entre o representante político e o cidadão comum.

\section{CONSIDERAÇốES FINAIS}

Para corrigir os efeitos nocivos desse progresso tecnológico, não precisamos retornar à ferramenta manual, suprimindo o trabalho das máquinas - o que seria táo absurdo e impossível, como deixar de usar o notebook para voltar à máquina de escrever! Não, o que precisamos é que a humanidade se esforce por simplificar sua existência com tanto frenesi quanto ela empregou em complicá-la. Apesar de tudo, vemos alguns tímidos indícios: uso de bike, preferência por uma alimentação natural, políticas de sustentabilidade etc. Nesse retorno à simplicidade, a máquina seria nossa maior aliada.

Não é, portanto, a força do destino nem o progresso das máquinas, mas somente a iniciativa da humanidade que lançou nessa direção o espírito de

\footnotetext{
${ }^{8}$ Devemos concordar com Rousseau: a liberdade do homem em estado de natureza é completamente diferente da liberdade que gozamos na sociedade civil. Ficar um dia sem celular e sem acesso à Internet pode servir-nos como parâmetro para avaliar o grau de dependência que temos dessas tecnologias, para além das transformaçōes que elas operaram nas relaçōes sociais (ROUSSEAU, 2006).
} 
invenção. Assim, o impulso que nos levou na direçáo do industrialismo pode ser compreendido como um desvio que, de início, era imperceptível, mas que, com o tempo, isto é, no estágio atual, revela um afastamento considerável da aspiração da humanidade como um todo.

$\mathrm{O}$ ato de resistência que encontramos na filosofia de Bergson não nos convencerá de nada. E, mesmo que nos convença, não teremos forças para nadar contra a corrente. Contudo, não se trata de um ato filosófico isolado, na voz de um pensador francês esquecido. A metáfora de Walter Benjamin renova essa ideia com a força de uma obra de arte vanguardista: "Marx havia dito que as revoluçôes são a locomotiva da história mundial. Mas talvez as coisas se apresentem de maneira completamente diferente. É possível que as revoluçóes sejam o ato, pela humanidade que viaja nesse trem, de puxar os freios de emergência.”(LÖWY, 2005, p. 93-94)

Nesse sentido, os discursos de José Mujica, ex-presidente de Uruguai mas, sobretudo, seus atos -, denotam um modo de vida simples que contrasta com a pompa e a ostentação que prevalecem na vida política contemporânea. ${ }^{9}$ Algo dessa lucidez faz eco da frase de Bergson: "O que é luxo para alguns é uma necessidade para outros”. Agora, falta o povo, isto é, a coragem necessária para resistir às palavras de ordem que configuram a estrada da sociedade atual.

ZUNINO, Pablo Enrique Abrahan. Intuition and Creation: Philosophy as an Act of Resistance. Tans/form/ação, Marília, v. 40, n. 4, p. 155-166, Out./Dez., 2017.

\begin{abstract}
The aim of this article is to ask how philosophy can be understood as an act of resistance. Deleuze introduces this thesis approaching philosophy to art, because both of them are acts of creation. In this sense, the philosophical method of Bergson - intuition - already indicates a kind of philosophical activity which is characterized above all by the creation of concepts. So how could a philosophical concept be an act of resistance? To answer this question, we return to an analysis of the relationship between intuition method and artistic creation, forward by Deleuze's interpretation of what it means to have an idea. However, the passage from idea to the act of resistance requires a transposition of the theoretical field to the concrete field. With this purpose, we focus on an example suggested by the philosophy of Bergson: the idea of a possible return to the simple life. This will allow us to evaluate the extent to which an idea can be confronted with the reality in today's world and, accordingly, be understood as an act of resistance.
\end{abstract}

KEYWORDS: Philosophy. Art. Creation. Resistance. Simple life.

\footnotetext{
${ }^{9}$ Este artigo foi escrito em 2014, portanto, durante a vigência do seu mandato como presidente (1 de março de 2010 - 1 de março de 2015).
} 


\section{REFERÊNCIAS}

BERGSON, H. As duas fontes da moral e da religiāo. Tradução de Nathanael Caxeiro. São Paulo: Abril Cultural, 1979. Cap. IV. (Os Pensadores). . O pensamento e o movente. São Paulo: Martins Fontes, 2006.

Les deux sources de la morale et de la religion. Paris: PUF, 2008 (Col. Le choc Bergson-Édition critique).

DELEUZE, G. Cinema I: a imagem-movimento. São Paulo: Brasiliense, 1985.

. Cinema II: a imagem-tempo. São Paulo: Brasiliense, 1990.

. Conversaçôes. Rio de Janeiro: Ed. 34, 1992.

. O ato de criação. Folha de S. Paulo, São Paulo, 27 jun. 1999. Caderno Mais!

; GUATTARI, F. O que é a filosofia? Rio de. Janeiro: Ed. 34, 1992.

FOUCAULT, M. Vigiar e punir: história da violência nas prisões. Petrópolis: Vozes, 1999.

GOUHIER, H. Bergson dans l'histoire de la pensée occidentale. Paris: Vrin, 1989.

HUXLEY, A. L. Admirável mundo novo. São Paulo: Globo, 1995.

KASTRUP, V. Flutuaçôes da atenção no processo de criação. In: LECERF, E. et. al. (Org.). Imagens da imanência: escritos em memória de H. Bergson. Belo Horizonte: Autêntica, 2007. p. 59-71.

LEOPOLDO E SILVA, F. Bergson: intuiçẫo e discurso filosófico. São Paulo: Loyola, 1994.

LÖWY, M. Walter Benjamin: aviso de incêndio: uma leitura das teses "sobre o conceito de história”. São Paulo: Boitempo, 2005.

MACHADO, R. Deleuze, a arte e a filosofia. Rio de Janeiro: Zahar, 2009.

ORWELL, G. 1984. São Paulo: Editora Nacional, 2003.

ROUSSEAU. Discurso sobre a origem e os fundamentos da desigualdade entre os homens. Sáo Paulo: Martins Fontes, 2006.

WATERLOT, G (Org.). Bergson et la religion: nouvelles perspectives sur les deux sources de la morale et de la religion'. Paris: PUF, 2008.

ZUNINO, P. Notas sobre a técnica: Heidegger e Bergson. In: COLÓQUIO HEIDEGGER DA UEFS, 1., Feira de Santana, BA, outubro de 2014.

. Estética e percepçấo em Bergson: a arte como modelo da filosofia. In: CARVALHO, M. et al. (Org.). Filosofia francesa contemporânea. Sáo Paulo: ANPOF, 2015. v. 1. 682p.

Recebido em 11/08/2015

Aceito em 23/06/2016 